\title{
Influence of the ice growth rate on the incorporation of gaseous $\mathrm{HCl}$
}

\author{
F. Domine ${ }^{1}$ and C. Rauzy ${ }^{1,2}$ \\ ${ }^{1}$ CNRS, Laboratoire de Glaciologie et Geophysique de l'Environnement, BP 96, 38402 Saint Martin d'Hères cedex, France \\ ${ }^{2}$ now at: Department of Chemistry, University of Fribourg, CH-1700 Fribourg, Switzerland
}

Received: 3 June 2004 - Published in Atmos. Chem. Phys. Discuss.: 23 August 2004

Revised: 22 October 2004 - Accepted: 8 December 2004 - Published: 10 December 2004

\begin{abstract}
Ice crystals were grown in the laboratory at $-15^{\circ} \mathrm{C}$, at different growth rates and in the presence of a partial pressure of $\mathrm{HCl}$ of $1.63 \times 10^{-3} \mathrm{~Pa}$, to test whether the ice growth rate influences the amount of $\mathrm{HCl}$ taken up, $X_{\mathrm{HCl}}$, as predicted by the ice growth mechanism of Domine and Thibert (1996). The plot of $\mathrm{HCl}$ concentration in ice as a function of growth rate has the aspect predicted by that mechanism: $X_{\mathrm{HCl}}$ decreases with increasing growth rate, from a value that depends on thermodynamic equilibrium to a value that depends only on kinetic factors. The height of the growth steps of the ice crystals is determined to be about $150 \mathrm{~nm}$ from these experiments. We discuss that the application of these laboratory experiments to cloud ice crystals and to snow metamorphism is not quantitatively possible at this stage, because the physical variables that determine crystal growth in nature, and in particular the step height, are not known. Qualitative applications are attempted for $\mathrm{HCl}$ and $\mathrm{HNO}_{3}$ incorporation in cloud ice and snowpack crystals.
\end{abstract}

\section{Introduction}

The understanding of snow composition is crucial for numerous scientific fields such as ice core inversions (Domine et al., 1995; Legrand and Mayewski, 1997), air-snow interactions (Domine and Shepson, 2002), hydrology (Tranter et al., 1986; Cragin et al., 1993; Domine and Thibert, 1995) and ecology (Crittenden, 1998). Snow on the ground undergoes metamorphism, a set of physical processes which includes sublimation-condensation cycles that lead to changes in the size and shapes of snow crystals (Colbeck, 1982; Domine et al., 2003). These changes are caused mostly by the thermal gradient in the snow, that lead to water vapor fluxes, which in turn entrain gases dissolved in the crystalline lat-

Correspondence to: F. Domine

(florent@lgge.obs.ujf-grenoble.fr) tice of the snow crystals or adsorbed on their surface. Many studies monitoring the composition of the snow after deposition have observed significant changes in the concentration of gases contained in the snow phase (see for example Hutterli et al. (2002) and Perrier et al. (2002) for HCHO; Jacobi et al. (2002) for $\mathrm{HCHO}$ and $\mathrm{H}_{2} \mathrm{O}_{2}$; Domine et al. (1995) for $\mathrm{HCl}$; Rothlisberger et al. (2002) for $\mathrm{HNO}_{3}$ ). Many processes can be invoked to explain those changes : solid state diffusion out of snow crystals as suggested by Perrier et al. (2002) for $\mathrm{HCHO}$, release during metamorphism as suggested by Nakamura et al. (2000) in the case of $\mathrm{HNO}_{3}$, photolysis as suggested by Jones et al. (2001) for $\mathrm{HNO}_{3}$, and the release of desorbed species because of the decrease in the specific surface area of snow during metamorphism, as suggested theoretically for acetone by Domine et al. (2002) and for acetaldehyde from measurements by Houdier et al. (2002).

The purpose of this work is to contribute to the understanding of the role of metamorphism in the change in composition of snow crystals. The data obtained are also applicable to the composition of ice crystals in clouds. The mole fraction of gases dissolved in ice will be the result of kinetic and thermodynamic processes. Domine and Thibert (1996) have proposed a physical mechanism to predict the concentration of a dissolved gas as a function of the growth rate of the ice crystal and of the intrinsic properties of the gas. At very fast growth rates, the gas mole fraction in ice, $X_{\text {gas }}$, is predicted by condensation kinetics, and is then $X_{k i n}$ :

$X_{\text {kin }}=\frac{P_{\text {gas }} \gamma_{\text {gas }}}{P_{\mathrm{H}_{2} \mathrm{O} \gamma_{\mathrm{H}_{2} \mathrm{O}}}} \sqrt{\frac{M_{\mathrm{H}_{2} \mathrm{O}}}{M_{\text {gas }}}}$

where $P$ is the partial pressure, $\gamma$ is the uptake coefficient on the ice surface, $\mathrm{M}$ is the molar mass, and the subscripts $\mathrm{H}_{2} \mathrm{O}$ and gas pertain to water and the dissolved gas, respectively. Domine and Thibert (1996) actually used $\alpha$, the mass accommodation coefficient, rather than $\gamma$. However, both in the atmosphere and in many laboratory setups, the observed

(C) 2004 Author(s). This work is licensed under a Creative Commons License. 


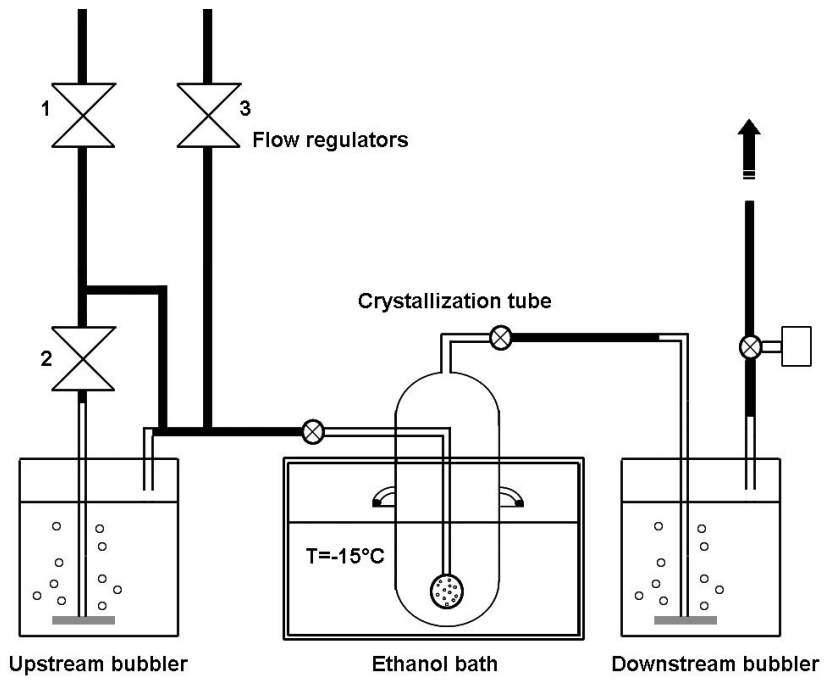

Fig. 1. Experimental system used to study the incorporation of $\mathrm{HCl}$ in growing ice crystals. Three flow regulators and a bubbler filled with ultra pure water are used to set the partial pressures of $\mathrm{HCl}$ and $\mathrm{H}_{2} \mathrm{O}$ diluted in $\mathrm{N}_{2}$ at atmospheric pressure. The crystallization tube is partly immersed in an ethanol bath at $-15^{\circ} \mathrm{C}$. A second bubbler is sometimes added downstream of the cold bath to trap $\mathrm{HCl}$.

uptake results from numerous factors that include the surface accommodation itself, but also limitations due to diffusion in the gas phase, desorption and solid state diffusion (Hanson, 1997; Ammann et al., 2003), so that it is more appropriate to use the variable $\gamma$, that is not influenced just by surface processes, and that represents a better description of observations in many systems.

At very slow growth rates, $X_{\text {gas }}$ is determined by the thermodynamics of the solid solution of the gas in ice, that predict $X_{e q}=f\left(T, P_{\text {gas }}\right)$, where $T$ is temperature and $X_{e q}$ is the mole fraction of the gas dissolved in ice at thermodynamic equilibrium. This is known for $\mathrm{HCl}$ and $\mathrm{HNO}_{3}$ (Thibert and Domine, 1997 and 1998). For $\mathrm{HCl}$, this relationship is:

$X_{\mathrm{HCl}}=6.1310^{-10} e^{\left(\frac{2806.5}{T}\right)}\left(P_{\mathrm{HCl}}\right)^{\frac{1}{2.73}}$

with $T$ in Kelvin and $P_{\mathrm{HCl}}$ in $\mathrm{Pa}$.

In many cases, however, both kinetic and thermodynamic factors contribute to $X_{\text {gas }}$. Domine and Thibert (1996) mentioned that under atmospheric conditions, the growth of ice crystals is a discontinuous process that takes place by the propagation of new growth steps nucleating at crystal edges. Each new step, of thickness $h$, is then formed with a composition $X_{k i n}$ determined by (1). Since this is out of equilibrium with the atmosphere, solid state diffusion of the gas in the ice lattice will take place to drive the composition towards $X_{e q}$. Equilibration can proceed during a duration $\tau$, after which a new ice layer is deposited, isolating the lower layer from the atmosphere and blocking diffusion from the gas phase. The resulting $X_{\text {gas }}$ value is then given by :

$X_{g a s}=X_{k i n}+\frac{\left(X_{e q}-X_{k i n}\right)}{h} \int_{0}^{h} \operatorname{erfc}\left(x / 2 \sqrt{D_{\text {gas }} \tau}\right) d x$

where $D_{\text {gas }}$ is the diffusion coefficient of the gas in ice and erfc is the complementary error function. In the case of $\mathrm{HCl}$, under most tropospheric conditions $X_{k i n}<<X_{e q}$, and Eq. (3) thus predicts that at slow growth rates, $X_{\mathrm{HCl}}$ will be higher than at fast growth rates. Thus, in a snowpack undergoing intense metamorphism driven by a strong temperature gradient leading to fast crystal growth (Domine et al., 2003), $X_{\mathrm{HCl}}$ of snow should be lower than in a snowpack subjected to a low temperature gradient, where crystal growth will be slow. In clouds, where crystal growth is almost always faster than in the snowpack, this predicts that $\mathrm{HCl}$ concentration will be mostly determined by kinetic factors, as observed by Domine and Thibert (1996).

In this paper, we describe laboratory experiments that test semi-quantitatively the model of Domine and Thibert. A fully quantitative test would require the monitoring of the step thickness and also the understanding of the various factors that control variations in the sticking coefficient of gases on solid surfaces, such as the state and defect density of the surface and the growth rate of the solid (Henderson, 2002). This would involve extensive instrumentation in surface science and solid state physics, and is well beyond the scope of the paper, whose objective is limited to testing that the growth rate of an ice crystal does indeed condition the incorporation of dopants. We thus grew ice crystals at several growth rates in the presence of a fixed $P_{\mathrm{HCl}}$. $\mathrm{HCl}$ was chosen because its solid solution with ice has been extensively studied, and its diffusion coefficient in ice is known (Thibert and Domine, 1997). From the data, we also attempt to determine $h$, the height of the growth steps in our experimental system.

\section{Experimental methods}

Gas mixtures of $\mathrm{H}_{2} \mathrm{O}$ and $\mathrm{HCl}$ diluted in $\mathrm{N}_{2}$ were flowed into a crystallization tube as shown in Fig. 1. The upstream bubbler was filled with ultra pure water (resistivity $>18 \mathrm{M} \Omega \mathrm{cm}$ ), placed in a dewar thermostated at $0^{\circ} \mathrm{C}$, and the $\mathrm{N}_{2}$ flow through that bubbler was adjusted to obtain the desired supersaturation in the crystallization tube, and this controlled the growth rate. Supersaturation values of the incoming mixture were determined from the data of Marti and Mauersberger (1993) and from the temperature of the stirred ethanol bath, regulated within $0.01^{\circ} \mathrm{C}$. The error in the supersaturation was determined by the error in the bath temperature and by the precision of the flow regulators $(4 \%)$, and was less than $10 \%$. $\mathrm{HCl}$ came from two commercial mixtures (Air Liquide) of $\mathrm{HCl}$ in $\mathrm{N}_{2}$ of molar concentrations 9.9 and $45.6 \mathrm{ppm}$. These concentrations were verified by flowing known amounts of mixture in the downstream bubbler, 
Table 1. Experimental conditions and results for the incorporation of $\mathrm{HCl}$ in ice as a function of the supersaturation of the gas mixture in $\mathrm{H}_{2} \mathrm{O}$ relative to ice at $-15^{\circ} \mathrm{C}$.

\begin{tabular}{|c|c|c|c|c|c|c|}
\hline $\begin{array}{l}\text { Experiment } \\
\text { duration } \\
\mathrm{h}\end{array}$ & $\begin{array}{c}\text { Supersaturation } \\
\qquad\end{array}$ & $\begin{array}{r}P_{\mathrm{H}_{2} \mathrm{O}} \\
\mathrm{Pa}\end{array}$ & $\begin{array}{c}P_{\mathrm{HCl}} \\
\mathrm{Pa}\end{array}$ & $\begin{array}{l}\text { Number of } \\
\text { experiments }\end{array}$ & $\begin{array}{c}\text { Average }\left[\mathrm{Cl}^{-}\right] \\
\text {(blank subtracted) } \\
\text { ppb molar }\end{array}$ & $\begin{array}{l}\text { Standard } \\
\text { deviation } \\
\text { ppb molar }\end{array}$ \\
\hline 64 & 15 & 190 & $1.67 \times 10^{-3}$ & 4 & 155 & 48 \\
\hline 26 & 40 & 231 & $1.67 \times 10^{-3}$ & 1 & 24 & - \\
\hline 16 & 82.5 & 301 & $1.67 \times 10^{-3}$ & 5 & 11 & 7 \\
\hline
\end{tabular}

followed by determination of the $\mathrm{Cl}^{-}$content by ion chromatography. Under the conditions used, the $\mathrm{HCl}$ in the bubbler water remained very unsaturated relative to the gas phase (Fritz and Fuget, 1956), so that all the $\mathrm{HCl}$ was effectively trapped in the bubbler. The crystallization tube had an internal diameter of $5 \mathrm{~cm}$ and the gas mixture flowed into it at a rate of $1.5 \mathrm{~L} /$ minute through a glass sphere $1.5 \mathrm{~cm}$ in diameter (Fig. 1) where 20 holes had been made to maximize turbulent mixing in the tube. The temperature of the ball was not measured. Its value was the result of heat exchanges between the warm incoming gases and the cold reactor walls. Since experiments at supersaturations of $82.5 \%$ did not result in ice formation on the ball, we deduce that its temperature was $>-8.4^{\circ} \mathrm{C}$. The pressure in the crystallization tube was about 960 mbar. The ice growing on the tube inner surface formed small $(<0.5 \mathrm{~mm})$ crystals whose detailed morphology could not be observed at the bottom of the tube. The ice stopped growing abruptly at the level of immersion of the tube, and appeared to form a layer of homogeneous thickness where it grew. The maximum mass of ice that could form was predicted from the supersaturation and the gas flow rate, and this was equal to the measured mass of ice, within $15 \%$. Two methods were used to retrieve the solid solution of $\mathrm{HCl}$ in ice formed: melting in the tube followed by analysis, and scraping of the inside of the tube in a cold room at $-15^{\circ} \mathrm{C}$ followed by analysis by ion chromatography using a Dionex 4000i instrument located in a clean room. Both methods produced similar results. Numerous tests and blanks were performed to identify and minimize possible sources of contamination.

Eight blank runs with no $\mathrm{HCl}$ were performed under flow conditions similar to the experiments with $\mathrm{HCl} \mathrm{Cl}^{-}$concentrations in the ice of these blanks ranged from 2 to $910^{-9}$ mole fraction (hereafter $\mathrm{ppb}$ ) with an average of $5 \mathrm{ppb} . \mathrm{Cl}^{-}$ was below detection limit $(0.5 \mathrm{ppb})$ in the water poured into the bubblers, and the source of the contamination was not clearly identified. Tests showed the $\mathrm{N}_{2}$, obtained from evaporating liquid $\mathrm{N}_{2}$, to be very clean. We rather believe that it is caused by $\mathrm{HCl}$ released from tubing or from flowmeters, that are difficult to clean perfectly, as $\mathrm{HCl}$ readily sticks to surfaces. In any case, the blank values were significantly

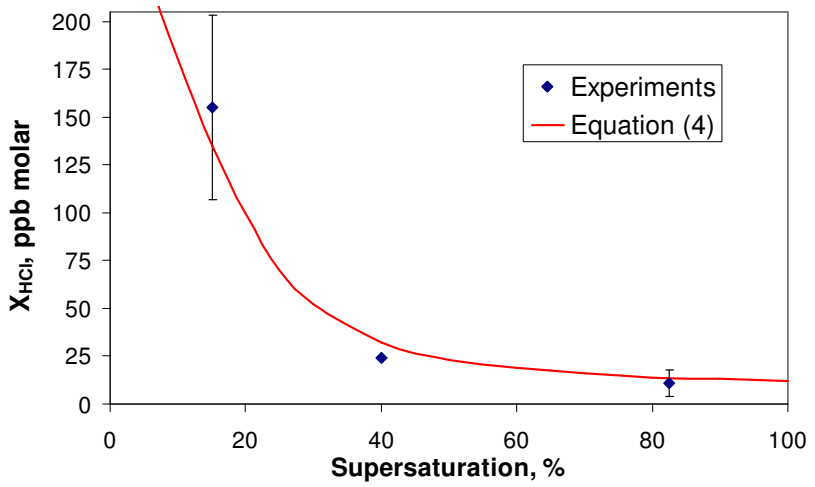

Fig. 2. Molar fraction of $\mathrm{HCl}$ (detected as $\mathrm{Cl}^{-}$by ion chromatography) in ice as a function of the supersaturation of the gas mixture relative to ice at $-15^{\circ} \mathrm{C}$. Error bars are the standard deviations when several experiments were made (see Table 1). The experimental data are compared to the predictions of Eq. (4), using values of $A, h, D_{g a s}, X_{k i n}$ and $X_{e q}$ detailed in the text.

lower than the signal, and were simply subtracted from the experimental values.

Before each experiment, the gas lines and the crystallization tube were conditioned by flowing the experimental mixture through them at room temperature for at least one hour.

\section{Results and discussion}

Since our objective was to study the impact of the ice growth rate on $\mathrm{HCl}$ incorporation, 10 experiments were performed by varying the water supersaturation, and hence the ice growth rates, while maintaining total flow, temperature, and $P_{\mathrm{HCl}}$ constant. Results obtained at $\mathrm{T}=-15^{\circ} \mathrm{C}$, for $P_{H C l}=1.67 \times 10^{-3} \mathrm{~Pa}$ are shown in Table 1 for supersaturations of 15,40 , and $82.5 \%$. Under those conditions, the equilibrium $\mathrm{HCl}$ mole fraction in ice is $X_{e q}=3120 \mathrm{ppb}$ (Thibert and Domine, 1997). The values obtained after subtracting blank values are between 11 and $155 \mathrm{ppb}$, much lower than $X_{e q}$, indicating that kinetic processes play an important role 
in determining $X_{\mathrm{HCl}}$. Figure 2 shows a plot of the 3 values of $X_{\mathrm{HCl}}$ as a function of supersaturation.

These data were used to test the validity of Eq. (3) and to determine the value of $h$, the height of the ice growth step. To compare our experimental data to this equation, we need to express $X_{\text {gas }}$ as a function of the water vapor supersaturation, $S$. We assume here that the linear growth rate of the ice, $v$, is proportional to $S$, so that $v=A \times S$. The growth rate $v$ and $h$ are related by $\tau=h / v$, so that $\tau=h / A S$, and Eq. (3) can be written as :

$X_{\text {gas }}=X_{\text {kin }}+\frac{\left(X_{\text {eq }}-X_{\text {kin }}\right)}{h} \int_{0}^{h} \operatorname{erfc}\left(x \sqrt{A S} / 2 \sqrt{D_{\text {gas }} h}\right) d x$

which relates $X_{\text {gas }}$ to $S$. To plot Eq. (4), we need to evaluate $A, D_{\text {gas }}$ and $h$. The growth rate can be inferred from the mass of ice that was retrieved and the surface area over which it grew. For the experiments at $15 \%$ supersaturation, the growth rate found was about $1 \mu \mathrm{m} / \mathrm{s}$, from which we deduce that $A=6.7 \times 10^{-6} \mu \mathrm{m} \mathrm{s}^{-1}$. At $-15^{\circ} \mathrm{C}$, the diffusion coefficient of $\mathrm{HCl}$ in ice is about $2 \times 10^{-12} \mathrm{~cm}^{2} / \mathrm{s}$ (Thibert and Domine, 1997). Other values have been proposed for this parameter, but Thibert and Domine (1997) and subsequently Domine and Xueref (2001) have explained in detail why those other values are highly questionable. The height of the growth step, $h$, was determined by solving numerically Eq. (3) using the data at $15 \%$ supersaturation, and also by optimizing the agreement between the curve and the experimental data. A value of $h=150 \mathrm{~nm}$ was obtained using either method, and the resulting curve is shown in Fig. 2, where the agreement with the data is good, given the experimental uncertainty. In this curve, a value of $X_{k i n}=11 \mathrm{ppb}$ was used. A somewhat lower value may slightly improve the fit, but not in a meaningful manner given the experimental uncertainties. Equation (4) indicates that the supersaturation required to approach equilibrium is around $0.1 \%$, which is not achievable in our experimental setup, as growth would be much too slow.

The value of $h$ that we deduce here is of the same order of magnitude as that found by Hallett (1961), who grew ice crystals on covellite surfaces and measured $h$ values of 20 to $100 \mathrm{~nm}$. However, most of these early studies focused on the basal face, while at our experimental temperature of $-15^{\circ} \mathrm{C}$, growth takes place on the prism face. In any case, crystal growth parameters are influenced by numerous variables such as growth rate, the nature of the surface on which crystals are grown, the crystallographic face and the defect density, so that there is little reason why values of $h$ found in one study should be reproduced in another study using different experimental conditions.

Equation (3) was derived to have a general validity. At fast growth rates, such as obtained for a supersaturation of $82.5 \%$, it simplifies to Eq. (1), which can then be used to estimate $\gamma_{\mathrm{HCl}} \gamma_{\mathrm{H}_{2} \mathrm{O}}$ on ice. We obtain a value of 0.0028 . We note that this value is very different from what would be expected if surface processes only were operative, and mass accommodation coefficients $\alpha$ could be used to predict $X_{k i n}$. The parameter $\alpha_{\mathrm{HCl}}$ has been measured in the laboratory around $-80^{\circ} \mathrm{C}$, and values between 0.1 and 1 have been found (Leu et al., 1988; Hanson and Ravishankara, 1992). Similarly, $\alpha_{\mathrm{H}_{2} \mathrm{O}}$ is in the range 0.1 to 1 (Haynes et al., 1992 and references therein), so that $\alpha_{\mathrm{HCl}} / \alpha_{\mathrm{H}_{2} \mathrm{O}}$ is expected to be in the range 0.1 to 10 . If surface processes only determine $\mathrm{HCl}$ uptake, $\gamma_{\mathrm{HCl}} / \gamma_{\mathrm{H}_{2} \mathrm{O}}$ would then be expected to be between 10 and 0.1 . Why the $\mathrm{HCl}$ content of our ice samples is so low at fast growth rates deserves discussion.

The first thought is that gas phase diffusion may be limiting. To a first approximation, this process should affect both $\mathrm{HCl}$ and $\mathrm{H}_{2} \mathrm{O}$ because $\alpha_{\mathrm{H}_{2} \mathrm{O}}$ and $\alpha_{\mathrm{HCl}}$ are of the same order of magnitude. However, essentially all of the excess $\mathrm{H}_{2} \mathrm{O}$ condensed in our tube, indicating that gas phase diffusion limitations in this turbulent reactor did not affect $\mathrm{H}_{2} \mathrm{O}$. We thus do not expect diffusion to limit $\mathrm{HCl}$ uptake either. Moreover, the fraction of $\mathrm{HCl}$ transferred from the gas phase to the ice phase is smaller than that of $\mathrm{H}_{2} \mathrm{O}$. Indeed, $\mathrm{P}_{\mathrm{HCl}} / \mathrm{P}_{\mathrm{H}_{2} \mathrm{O}}$ is always around $10^{-5}$, while $X_{\mathrm{HCl}}$ is about $10^{-8}$ in this fast growth experiment, so that gaseous $\mathrm{HCl}$ will be much less depleted than $\mathrm{H}_{2} \mathrm{O}$ in the vicinity of the ice surface. Since we observed that the loss of $\mathrm{HCl}$ is much smaller than that of $\mathrm{H}_{2} \mathrm{O}, \mathrm{HCl}$ is necessarily less affected by diffusion limitations than $\mathrm{H}_{2} \mathrm{O}$, and this process probably cannot explain our low $\gamma$ ratio. Desorption of $\mathrm{HCl}$ must then be responsible for the low $\gamma$ ratio.

To evaluate quantitatively this desorption, a budget of $\mathrm{HCl}$ at the ice surface must be established. This cannot be done, because we only have an approximate value of $\alpha_{\mathrm{HCl}}$. However, in the fast growth experiment, the mole fraction of $\mathrm{HCl}$ in the gas phase is about $5 \times 10^{-6}$, while it is about $10^{-8}$ in the solid phase. If $\alpha_{\mathrm{H}_{2} \mathrm{O}}$ and $\alpha_{\mathrm{HCl}}$ were equal, this would mean that $99.8 \%$ of the $\mathrm{HCl}$ that initially adsorbs subsequently desorbs before being incorporated in ice.

Santachiara et al. (1995) also studied the incorporation of $\mathrm{HCl}$ in ice crystals growing by the Bergeron mechanism from water droplets containing $\mathrm{HCl}$ in a diffusion chamber at $-13^{\circ} \mathrm{C}$. They found $X_{\mathrm{HCl}}$ values up to $3000 \mathrm{ppm}$, much higher than the maximum thermodynamic solubility (Thibert and Domine, 1997). However, they induced ice nucleation by introducing "a small metal bar cooled in liquid nitrogen" in their chamber, creating a cold spot. It then seems that neither the crystal growth temperature, nor $P_{\mathrm{HCl}}$ can be determined, and it is not possible to compare their results with ours.

Diehl et al. (1995) grew ice crystals from water vapor at $-15^{\circ} \mathrm{C}$, with a supersaturation estimated at about $15 \%$ in a diffusion chamber, and in the presence of $\mathrm{HCl}$. Their lowest $P_{\mathrm{HCl}}$ was about $5 \times 10^{-3} \mathrm{~Pa}$, and the resulting $X_{\mathrm{HCl}}$ was about $200 \mathrm{ppb}$. Besides $P_{\mathrm{HCl}}$, their conditions are similar to our experiments at $15 \%$ supersaturation, and we found $155 \mathrm{ppb}$ under $P_{\mathrm{HCl}}=1.67 \times 10^{-3} \mathrm{~Pa}$. If we compare their results to ours according to Eq. (1), i.e. assuming that kinetic processes rule incorporation, then their concentration is a factor of 2.3 
lower than expected from our results. On the other hand, if the comparison is done using Eq. (2), i.e. using a $P_{\mathrm{HCl}}^{\frac{1}{2.73}}$ dependence, then their result should be 1.5 times greater than ours, i.e. $232 \mathrm{ppb}$, definitely within the overlap of their error bars and ours. Since Diehl et al. (1995) used a set up very different from ours that could result in a different value of $h$, and since according to Eq. (3) the value of $h$ greatly influences $X_{\mathrm{HCl}}$, we conclude that the $X_{\mathrm{HCl}}$ value of Diehl et al. is compatible with ours. However, their purpose was not to test the impact of the growth rate on $\mathrm{HCl}$ incorporation, and their data can thus not be used to test our mechanism.

The variability of crystal growth parameters such as $h$, but also $\alpha_{\mathrm{H}_{2} \mathrm{O}}$ and $\alpha_{\mathrm{HCl}}$, with experimental conditions thus makes it difficult to intercompare experiments. The application of laboratory data to natural conditions is even more delicate and deserves a separate discussion.

\section{Application to snowpacks and clouds}

The main conclusion of this work is that the experimental data obtained is consistent with the mechanism of Domine and Thibert (1996), which showed that the composition of ice depends on its growth rate and on the details of its growth mechanism. Given that we have argued that the variables that determine the growth of snow crystals, and hence the incorporation of trace gases, vary between different laboratory experiments, and presumably between the different conditions encountered in clouds and in snowpacks, quantitative application of this mechanism to the natural environment appears impossible until we understand the details of ice crystal growth in nature, and we seem to be very far from this goal. Domine et al. (2003) may have observed growth steps on surface hoar crystals studied by scanning electron microscopy (SEM), and whose height was about $1 \mu \mathrm{m}$, but it is not even totally certain that the structures observed were growth steps, and they did not seem to originate from a crystal edge, but rather from a grain boundary, so that the representativity of this observation may be limited. Indeed, the numerous SEM studies of snow crystals (Wergin et al., 1996; Domine et al., 2003; Erbe et al., 2003; Legagneux et al., 2003) usually do not show any structures that can be convincingly attributed to growth steps, which suggest that these could be undetectable by SEM and much smaller than $1 \mu \mathrm{m}$ in most cases.

Furthermore, in nature, the ice surface and the adsorption of trace gases can be modified by the presence of numerous pollutants. For example Hynes et al. (2002) have observed that adsorbed $\mathrm{HCl}$ was displaced from the ice surface in the presence of $\mathrm{HNO}_{3}$. The ubiquitous sulphate aerosols can also be scavenged by ice surfaces and form a liquid or disordered film that could dramatically modify ice surfaces and the incorporation of trace gases, as the first step in incorporation is adsorption.

Given our limited understanding of the growth of snow crystals in nature, we are limited to speculate qualitatively on the interactions between crystal growth rate and chemical composition. For species highly soluble in ice such as $\mathrm{HCl}, X_{k i n}<X_{e q}$ under most atmospheric conditions and faster growth rates will lead to lower concentrations. Thus, the small columnar ice crystals that form slowly in cirrus clouds at low temperature should be more concentrated in $\mathrm{Cl}^{-}$than the larger dendritic crystals that grow rapidly in the warmer stratiform clouds. In the snowpack, the rapidly growing depth hoar crystals should be depleted in $\mathrm{Cl}^{-}$relative to windpack crystals, that grow much more slowly. This should be true at least in acidic snow, where the $\mathrm{Cl}^{-}$measured by ion chromatography indeed reflects $\mathrm{HCl}$ content, while it would have little reason to hold in alkaline snow, where the $\mathrm{Cl}^{-}$ signal reflects the content of particulate $\mathrm{Cl}^{-}$, present in snow as salts such as $\mathrm{NaCl}$. Field measurements of different snow crystal types in a given snow pack would be a feasible test of this prediction.

The situation is probably different for $\mathrm{HNO}_{3}$, which is about 20 times less soluble in ice than $\mathrm{HCl}$ (Thibert and Domine, 1998). In this case, the data available suggest that at high temperature, we still have $X_{k i n}<X_{e q}$, but at low temperature, we should have $X_{k i n}>X_{e q}$. The limit between "high" and "low" temperature will depend on the physics of ice crystal growth, and particularly on $h$. In the Arctic or subarctic snowpack, since depth hoar crystals are at the relatively warm bottom part of the snowpack while windpacks are at the colder top part (Domine et al., 2002), we have all reasons to expect a higher $\mathrm{NO}_{3}^{-}$concentration in the windpack, and again this prediction applies only to acidic snow.

\section{Conclusions}

The experiments performed here are consistent with the predictions of the mechanism of Domine and Thibert (1996) that proposed an interaction between the growth rate of ice crystals and their chemical composition. The nature of the crystallographic face, the nucleation mechanism and step height, $h$, of new ice layers, and other variables describing the state of the growing ice surface will influence ice composition. The immediate implication is that considerable efforts must be devoted to the physics of ice crystal growth under natural conditions if we want to understand the composition of ice crystals in clouds and in the snowpack.

It is also noteworthy that this mechanism does not need to invoke the much talked about "quasi-liquid layer" (QLL) on the ice surface. It is certain that this QLL does exist, as it has been evidenced by numerous techniques (Petrenko and Witworth, 1999), including a recent study by atomic force microscopy (Döppenschmidt and Butt, 2000) that concluded that its thickness at $-15^{\circ} \mathrm{C}$ was between 5 and $10 \mathrm{~nm}$. Several authors (e.g. Valdez et al., 1989; Conklin and Bales, 1993) have interpreted gas uptake by growing ice in terms of solubilization of the gas in the QLL, using thermodynamic parameters of actual liquid water. But the QLL properties 
are definitely different from those of liquid water, and using parameters measured for liquid water is unwarranted. Moreover, the model used by those authors led them to conclude that the QLL thickness in pure ice was greater than $100 \mathrm{~nm}$ at $-15^{\circ} \mathrm{C}$, in sharp contrast with the actual measurements of Döppenschmidt and Butt (2000). Further supporting the idea that the QLL need not be invoked to explain ice growth at $-15^{\circ} \mathrm{C}$, many physical properties of ice growth have been explained successfully by considering solid state processes only (Libbrecht, 2003a and b; Nelson and Baker, 2003; Nelson, 1998; Nelson and Knight, 1998).

Acknowledgements. This work was funded by CNRS through Programme National de Chimie Atmosphérique (PNCA). We thank M. de Angelis for help with the ion chromatography analyses.

Edited by: B. Kärcher

\section{References}

Ammann, M., Pöschl, U., and Rudich, Y.: effects of reversible adsorption and Langmuir-Hinshelwood surface reactions on gas uptake by atmospheric particles, Phys. Chem. Chem. Phys. 5, 351-356, 2003.

Colbeck, S. C.: An overview of seasonal snow metamorphism, Rev. Geophys. Space Phys., 20, 45-61, 1982.

Conklin, M. H. and Bales, R. C.: $\mathrm{SO}_{2}$ uptake on ice spheres: liquid nature of the ice-air interface, J. Geophys. Res. 98, 16851$16855,1993$.

Cragin, J. H., Hewitt, A. D., and Colbeck, S. C.: Elution of ions from melting snow: Chromatographic versus metamorphic mechanisms, CRREL Report 93-8, 20, 1993.

Crittenden, P. D.: Nutrient exchange in an Antarctic macrolichen during summer snowfall snow melt events, New Phytol., 139, 697-707, 1998.

Diehl, K., Mitra, S. K., and Pruppacher, H. R.: A laboratory study of the uptake of $\mathrm{HNO}_{3}$ and $\mathrm{HCl}$ vapor by snow crystals and ice spheres at temperatures between 0 and $-40^{\circ} \mathrm{C}$, Atmos. Environ., 29, 975-981, 1995.

Dominé, F. and Thibert, E.: Relationship between atmospheric composition and snow composition for $\mathrm{HCl}$ and $\mathrm{HNO}_{3}$, in: Biogeochemistry of seasonally snow-covered catchments, edited by: Tonnessen, K., Williams, M., and Tranter, M., Proceedings of a Boulder Symposium, IAHS Publ. No. 228, 3-10, 1995.

Dominé, F., Thibert, E., Silvente, E., Legrand, M., and Jaffrezo, J.L. : Determining past atmospheric $\mathrm{HCl}$ mixing ratios from ice core analyses, J. Atmos. Chem., 21, 165-186, 1995.

Dominé, F. and Thibert, E.: Mechanism of incorporation of trace gases in ice grown from the gas phase, Geophys. Res. Lett., 23, 3627-3630, 1996.

Dominé, F. and Xueref, I.: Evaluation of depth profiling using laser resonant desorption as a method to measure diffusion coefficients in ice, Anal. Chem., 73, 4348-4353, 2001.

Dominé, F., Cabanes, A., and Legagneux, L.: Structure, microphysics, and surface area of the Arctic snowpack near Alert during ALERT 2000, Atmos. Environ., 36, 2753-2765, 2002.

Dominé, F. and Shepson, P. B.: Air-snow interactions and atmospheric chemistry, Science, 297, 1506-1510, 2002.
Dominé, F., Lauzier, T., Cabanes, A., Legagneux, L., Kuhs, W. F., Techmer, K., and Heinrichs T.: Snow metamorphism as revealed by scanning electron microscopy, Microsc. Res. Tech., 62, 3348, 2003.

Döppenschmidt, A. and Butt, H.-J.: Measuring the thickness of the liquid-like layer on ice surfaces with atomic force microscopy, Langmuir, 16, 6709-6714, 2000.

Erbe, E. F., Rango, A., Foster, J., Josberger, E. G., Pooley, C., and Wergin, W. P.: Collecting, shipping, storing, and imaging snow crystals and ice grains with low-temperature scanning electron mircoscopy, Microsc. Res. Tech., 62, 19-32, 2003.

Fritz, J. J. and Fuget, C. R.: Vapor pressure of aqueous hydrogen chloride solutions, $0^{\circ}$ to $50^{\circ} \mathrm{C}$, Indust. Eng. Chem., 1, 10-12, 1956.

Hallett, J.: The growth of ice crystals on freshly cleaved covellite surfaces, Phil. Mag., 6, 1073-1087, 1961.

Hanson, D. R. and Ravishankara, A. R.: Investigation of the reactive and nonreactive processes involving $\mathrm{ClONO}_{2}$ and $\mathrm{HCl}$ on water and nitric acid doped ice, J. Phys. Chem., 96, 2682-2691, 1992.

Hanson, D.: Surface-specific reactions on liquids, J. Phys. Chem. B, 101, 4998-5001, 1997

Haynes, D. R., Tro, N. J., and George, S. M.: Condensation and evaporation of $\mathrm{H}_{2} \mathrm{O}$ on ice surfaces, J. Phys. Chem., 96, 85028509, 1992.

Henderson, M. A.: The interaction of water with solid surfaces: fundamental aspects revisited, Surface Sci. Rep., 46, 1-308, 2002.

Hobbs, P. V.: Ice Physics, Clarendon press, Oxford, 1974.

Houdier, S., Perrier, S., Dominé, F., Grannas, A. M., Guimbaud, C., Shepson, P. B., Boudries, H., and Bottenheim, J. W.: Acetaldehyde and acetone in the Arctic snowpack during the ALERT2000 field campaign, Snowpack composition, incorporation processes and atmospheric impact, Atmos. Environ., 36, 2609-2618, 2002.

Hutterli, M. A., Bales, R. C., McConnell, J. R., and Stewart, R. W.: $\mathrm{HCHO}$ in Antarctic snow: preservation in ice cores and air-snow exchange, Geophys. Res. Lett., 29, 76-1-76-4, 2002.

Hynes, R. G, Fernandez, M. F., and Cox, R. A.: The uptake of $\mathrm{HNO}_{3}$ on water ice and the co-adsorption of $\mathrm{HNO}_{3}$ and $\mathrm{HCl}$ in the Temperature range 210-235 K, J. Geophys. Res., 107, 4797, doi:10.1029/2001JD001557, 2002.

Jacobi, H.-W., Frey, M. M., Hutterli, M. A., Bales, R. C., Schrems, O., Cullen, N. J., Steffen, K., and Koehler, C.: Measurements of hydrogen peroxide and formaldehyde exchange between the atmosphere and surface snow at Summit, Greenland, Atmos. Environ., 36, 2619-2628, 2002.

Jones, A. E., Weller, R., Anderson, P. S., Jacobi, H.-W., Wolff, E. W., Schrems, O., and Miller, H.: Measurements of $\mathrm{NO}_{x}$ emissions from the Antarctic snowpack, Geophys. Res. Lett., 28, 1499-1502, 2001.

Legagneux, L., Lauzier, T., Dominé, F., Kuhs, W. F., Heinrichs, T., and Techmer, K.: Rate of decay of the specific surface area of snow during isothermal experiments and morphological changes studied by scanning electron microscopy, Can. J. Phys., 81, 459468, 2003.

Legrand, M. and Mayewski, P.: Glaciochemistry of polar ice cores: a review, Rev. Geophys., 35, 219-243, 1997.

Leu, M. T.: Laboratory studies of sticking coefficients and heterogeneous reactions important in the Antarctic stratosphere, Geophys. Res. Lett., 15, 17-20, 1988. 
Libbrecht, K. G.: Explaining the formation of thin ice crystal plates with structure-dependent attachment kinetics, J. Cryst. Growth, 258, 168-175, 2003a.

Libbrecht, K. G.: Growth rates of the principal facets of ice between $-10^{\circ} \mathrm{C}$ and $-40^{\circ} \mathrm{C}$, J. Cryst. Growth, 247, 530-540, $2003 \mathrm{~b}$.

Marti, J. and Mauersberger, K.: A survey and new measurements of ice vapor pressure at temperature between 170 and $250 \mathrm{~K}$, Geophys. Res. Lett., 20, 363-366, 1993.

Nakamura, K., Nakawo, M., Ageta, Y., Goto-Azuma, K., and Kamiyam, K.: Post-depositional loss of nitrate is surface snow layers of the Antarctic ice sheet, Bull. Glaciol. Res., 17, 11-16, 2000.

Nelson, J.: Sublimation of ice crystals, J. Atmos. Sci., 55, 910-919, 1998.

Nelson, J. and Knight, C.: Snow crystal habit change explained by layer nucleation, J. Atmos. Sci., 55, 1452-1465, 1998.

Nelson, H. and Baker, M. B.: Charging of ice-vapor interfaces: application to thunderstorms, Atmos. Chem. Phys., 3, 1237-1252, 2003,

SRef-ID: 1680-7324/acp/2003-3-1237.

Perrier, S., Houdier, S., Dominé, F., Cabanes, A., Legagneux, L., Sumner, A. L., and Shepson, P. B.: Formaldehyde in Arctic snow. Incorporation into ice particles and evolution in the snowpack, Atmos. Environ., 36, 2695-2705, 2002.

Petrenko, V. F. and Witworth, R. W.: Physics of ice, Oxford University Press: New York, 1999.
Rothlisberger, R., Hutterli, M. A., Wolff, E. W., Mulvaney, R., Fischer, H,. Bigler, M., Goto-Azuma, K., Hansson, M. E., Ruth, U., Siggaard-Andersen, M. L., and Steffensen, J. P.: Nitrate in Greenland and Antarctic ice cores: a detailed description of postdepositional processes, Annals Glaciol., 35, 209-216, 2002.

Santachiara, G., Prodi, F., and Vivarelli, F.: Scavenging of $\mathrm{SO}_{2}$ and $\mathrm{HCl}$ during growth of ice crystals by vapour diffusion, Atmos. Environ., 29, 983-987, 1995.

Thibert, E. and Dominé, F.: Thermodynamics and kinetics of the solid solution of $\mathrm{HCl}$ in ice, J. Phys. Chem. B, 101, 3554-3565, 1997.

Thibert, E. and Dominé, F.: Thermodynamics and kinetics of the solid solution of $\mathrm{HNO}_{3}$ in ice, J. Phys. Chem. B, 102, 44324439, 1998.

Tranter, M., Brimblecombe, P., Davies, T. D., Vincent, C. E., Abrahams, P. W., and Blackwood, I.: The composition of snowfall, snowpack and meltwater in the Scottish highlands - Evidence for preferential elution, Atmos. Environ., 20, 517-525, 1986.

Valdez, M. P., Dawson, G. A., and Bales, R. C.: Sulfur dioxide incorporation into ice depositing from the vapor, J. Geophys. Res., 94, 1095-1103, 1989.

Wergin, W. P., Rango A., Erbe, E. F., and Murphy, C. A.: Low Temperature S.E.M. of Precipitated and Metamorphosed Snow Crystals Collected and Transported from Remote Sites, J. Microsc. Soc. Amer., 2, 99-112, 1996. 